\title{
Professional Stress- A Cause for Addiction
}

\author{
Smita Nagle ${ }^{1}$, Sumit Maheshwari², Ankur Walli³, Radhika Sonate ${ }^{4}$ \\ ${ }^{1}$ Associate Professor, Department of ENT, Head and Neck Surgery, Grant Government Medical College, Mumbai, \\ Maharashtra, India. ${ }^{2}$ Resident, Department of ENT, Head and Neck Surgery, Grant Government Medical College, \\ Mumbai, Maharashtra, India. ${ }^{3}$ Resident, Resident, Department of ENT, Head and Neck Surgery, Grant Government \\ Medical College, Mumbai, Maharashtra, India. ${ }^{4}$ Resident, Resident, Department of ENT, Head and Neck Surgery, Grant \\ Government Medical College, Mumbai, Maharashtra, India.
}

\section{ABSTRACT}

\section{BACKGROUND}

Police personnel work throughout the day without rest. Because of this they are not getting enough family time, which leads to irritation, anxiety and depression. Eventually, these problems can lead to physical and mental stress, physical health problems like obesity, hypertension or may lead to some form of addiction.

\section{METHODS}

A cross sectional study was conducted among atotal of 400 policemen who came to outpatient department of Gokuldas Tejpal Hospital, Mumbai for general check-up. Data was collected using a specifically designed datasheet covering physical- and mental-health related details which was prepared by researchers and observers. Occupational stress was measured using questionnaire.

\section{RESULTS}

The study found that stress was significant among the police officers. Out of the 400 policemen 156 had alcohol addiction, 71 had smoking addiction and further other addictions.

\section{CONCLUSIONS}

The results describe the alarming level of occupational stress present in Indian police officers and the need for government and other organizations to act and tackle this occupational stress. The present study analyses the stress among police workers and its consequences (physical and mental) like alcoholism, smoking, tobacco consumption and obesity.

\section{KEY WORDS}

Policemen, Occupational Stress, Addiction
Corresponding Author: Dr. Sumit Maheshwari, Room No. 205, High Rise Building, GT Hospital, Mumbai-400001, Maharashtra, India.

E-mail: sumitmaheshwari1989@gmail.com

DOI: $10.14260 / \mathrm{jemds} / 2019 / 664$

Financial or Other Competing Interests: None.

How to Cite This Article:

Nagle S, Maheshwari S, Walli A, et al. Professional stress- $a$ cause for addiction. $J$. Evolution Med. Dent. Sci. 2019;8(41): 3052-3056, DOI: 10.14260/jemds/2019/664

Submission 26-02-2018, Peer Review 03-05-2019,

Acceptance 09-05-2019, Published 14-10-2019.

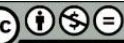




\section{BACKGROUND}

Police job is very stressful, and it is one of the hardest jobs in the world. $\{1\}$ The causes of stress are many- long duration of working hours, stressful working environment, very less family and leisure time, irregular and improper dietary habits, sleepless nights, insufficient rest, need to take tough decisions in a frequent of seconds, poor living and working conditions, grudges with seniors, inadequate time for other activities, problems in personal life etc. $\{2,3\}$ The police department is one of the few department where people face physical dangers and risk their lives for us. Occupational stress has the inverse relationship with the job satisfaction, i.e. higher the stressful job, lesser the job satisfaction, this relationship have been proved by many studies. $\left.{ }^{4}\right\}$ This relationship have consequences for any kind of department especially police department, because job dissatisfaction can directly lead to poorer level of commitments at work and increased number of resigning from jobs. Stress among police workers may present as substance addiction, depression, irritability, anxiety issues, restlessness, difficulty to concentrate, impulsive behaviour and other problems. Stress has a poor influence on both physical and mental wellbeing of employee which make them unfit for work and police job is one job which requires physical as well as mental health at its best, and it impacts their work performance. $\{5\}$ Occupational stress has become one of the most frequent and soon emerging to be one of the costliest health problem. ${ }^{6\}}$ Occupational stress and its consequences on physical and mental health of policemen are not addressed adequately and with proper methods by the government and concerned authorities in India. Policemen play a pivotal role in maintaining law and order in the society which leads to social welfare and despite of all the problems and limitations in the police department especially which includes damaged infrastructure facilities, work abuse by seniors, decreased manpower and improper periodic training. Policemen work round the clock and/or without any leave/break due to the need of the job and which leads to unbearable mental as well as physical tension which sometime may lead to breakdown of the person. [7 $^{\text {We }}$ wanted to study the effects of occupational stress on police officers and that stress leading to multiple substance abuse in them.

\section{METHODS}

\section{Study Type}

Cross Sectional Study.

\section{Study Setting}

OPD of Department of ENT \& Head and Neck Surgery, Gokuldas Tejpal Hospital, Mumbai.

\section{Sample Size}

Because of the exploratory nature of the study and time constraint, the total number of police officers included in this study was four hundred (400).

\section{Definition of Case}

Patient who reported to ENT outpatient department for routine health check-up.

\section{Sampling Technique}

Simple Prospective sampling method was applied to select the cases for the study.

\section{Data Collection}

After obtaining the written informed consent from the police officers who came for regular health check-up, presenting to ENT outpatient department of the Gokuldas Tejpal Hospital, Mumbai. When we started examination of the patient most of them had erythroplakic, leukoplakic patch, tobacco stained teeth, halitosis, oral submucous fibrosis. All above findings was used as a measure of Abuse. Then we enquired about detailed history of their lifestyle and dietary habits. Most of the subjects had some form of addiction like alcoholism, smoking, tobacco consumption. Surprisingly, this addiction was started after joining their profession and not from their college life or adolescent age that gave us a clue to do this study.

\section{Inclusion Criteria}

Police officers between 40 and 60 yrs. of age giving voluntary consent for study.

\section{Exclusion Criteria}

Police officers who refused to give a voluntary consent or who refused to give their detailed past history.

\section{Data Analysis}

The data obtained was sorted and categorized on the basis of demographic characteristics (Gender and Age). The information was compiled and analyzed by running frequency and chi-square analysis using SPSS version 16.00 . The $\mathrm{p}<0.05$ was considered significant.

\section{RESULTS}

\begin{tabular}{|c|c|c|}
\hline Addictions & $\begin{array}{c}\text { Number of Police Officers } \\
\text { Giving History }\end{array}$ & $\begin{array}{c}\text { \% of } \\
\text { Addictions }\end{array}$ \\
\hline Alcohol & 156 & $39 \%$ \\
\hline Smoking & 71 & $17.75 \%$ \\
\hline Alcohol and smoking & 74 & $18.5 \%$ \\
\hline Tobacco & 189 & $47.25 \%$ \\
\hline Alcohol, smoking and tobacco & 273 & $68.25 \%$ \\
\hline
\end{tabular}

Table 1. Various Types of Addictions, Number of Police Officers Giving History of Addiction and Prevalence of Specific Addictions Out of 400 Police officers 95 of them also showed obesity due to their faulty dietary habits.

\section{DISCUSSION}

There is a scarcity of knowledge on occupational stress and associated mental and physical health problems caused due to it. The results of our study clearly define that the occurrence of occupational stress among police officers in India is very high. Our results match with many other studies done in the same field. ${ }^{8\}}$ If not handled with care the stress can become severe distress for the employee as well as employer and in this study, it is police department. So it ultimately proceeds to harm the social well-being. The first category is the ability of the employee to work for the defined hours and at the level of efficiency expected at work. The 
second category is giving the perfect role to perfect employee to get desired results. Higher management should have a watch over the functioning of the department. The third category involves care and development of the employee such as job securities, timely promotion, recreational activities at work, etc. The fourth category involves the interpersonal relationship between the employer and employee, and between the colleagues, and between the seniors and their subordinates. . $^{9\}}$ These relationships can be positive or negative. Most common factors at workplace that causes stress are physical and mental harassment, discrimination, biased behaviour of employer towards certain employee and other derogatory remarks. Finally, the last category of occupational stress is the organizational structure.\{10\} The overall need of collaborative planning, good and definitive management by seniors leads to less absenteeism, increased work performance, good judgement in emergency situations, good results at work, better personal life and greater job satisfaction. Persistence of increased occupational stress is the dangerous situation which can explode anytime and give hazardous outcomes. It needs to be considered a major health issue. The continuous occupational stress will affect the crime solving rate and crime prevention rate as well as their personal life.

\section{Stress, Health and Disease}

Stress effects health and may lead to disease. There have been noteworthy study efforts to clarify the connection between stress and disease. While there is good epidemiologic evidence associating occupational stress with a number of disease conditions, the pathophysiological mechanisms often remain obscure, and in most situations, a true causal, relationship has not been demonstrated. There are various ongoing research efforts to establish the pathophysiological pathways through which stress may produce disease. Neurologic, immunologic, and endocrine mediators of disease have been established. The hypothalamic-pituitary axis, the autonomic nervous system and catecholamine response are often connected with stress sensitive system. Frequent adverse health effects include psychological disorders, cardiovascular disease, and gastrointestinal disease and, high levels of health service utilization etc.

\section{Psychological Disorders}

Stress related disorders comprises a variety of disorders which includes depression, post-traumatic stress disorder, dissatisfaction, physical and mental fatigue, etc. Behavioural problems such as irritation impulsivity, anxiety, multiple substance addictions, etc. Cognitive impairment such as concentration problems and memorizing problems. All the above-mentioned conditions may directly or indirectly lead to higher absenteeism, poor work performance, poor efficiency, poor productivity or even injury. If occupational stress left untreated it may become the chronic condition and may manifest as chronic mental disorders and chronic physical conditions such as diabetes, hypertension, obesity, hypo-functioning immune system.

\section{Cardiovascular Disease}

Occupational stress is also related to multiple biological reactions within the body which leads to poor physical health which further can lead to cardiovascular disease. Due to requirement of consistent high demands and higher work pressure. The studies have shown the higher rates of myocardial infarction episodes, angina attacks, hypertension and other cardiovascular disorders.

\section{Gastrointestinal Disease}

Peptic Ulcer Disease Has Been Associated with Stress, Although There Is Limited Recent Epidemiologic Information In This Area. The involvement of bacteria Helicobacter pylori as a causative factor in peptic ulcer disease has not removed consideration of stress as a possible cause. Gastric acid secretion in response to catecholamine stimulation may also be a contributing factor, although there is conflicting evidence on its significance/Stress may have an impact on wound healing as well as immune function. The importance of these factors in peptic ulcer disease should be further explored in studies.

\section{Health Service Utilization}

There is the considerable trend seen that higher the occupational stress leads to higher the health service utilization. From recent studies it has been proved that the periods of disability due to workplace stress are much longer than the disability due to other stress injuries and illness.

\section{Physiological Reaction}

Researchers are studying how the mental stress affects the cardiovascular system and also how the high occupational stress leads to higher incidence of obesity, hypertension, myocardial infarction and various other coronary heart diseases. These diseases are common along the Indian workplace.

\section{Physiological Reactions to Stress}

- Blood is directed to the brain and large muscle groups, and away from extremities, skin, and the organs that are not currently serving the body.

- An area near the brain stem, called as the reticular activating system, activates, which causes a state of high alertness as well as a higher hearing and vision for a considerable time.

- Energy providing compounds of glucose and fatty acid compounds are released into the blood stream to provide instant energy.

- The immune and digestive systems of body are shut down for meantime. $\{11\}$

\section{Causes of Stress}

There are multiple factors that can cause stress such as physical (fear of something dangerous), emotional (poor family life, job insecurities, lack of promotion at desirable time, problems with seniors). Finding the cause of stress is the first step towards the many steps to reduce someone's stress. Most common stress are:

A. Survival Stress: It works on the basic instinct of survival. If someone is fearful of something physically injuring him, body responds with energy outburst. So, a person can survive the situation by either fighting it or escaping it (Flight). 
B. Internal Stress: Have you ever felt anxious about things you can't control or worrying for no reason at all. This is called the internal stress. Internal stress is when a person makes themselves stressed by over thinking about the situation or put themselves in situation, they know will cause stress. Some people love the hurried, tense lifestyle that comes due to stressed situations. So, they do anything to get in stressed situations to get a adrenaline rush of tension life.

C. Environmental Stress: This is caused due to surrounding factors that cause stress such as noise, crowding and continuous pressure from work as well as family. Identifying these stress factors and dealing with them by managing it or keeping away from it helps us to reduce stress level.

D. Fatigue and Overwork: This kind of stress piles up over a long period of time and can take a significant pressure on your body. It occurs due to working too much and too hard at your job and home. It could also occur due to not getting acquainted with the task provided to them which leads to decreased work efficiency or not taking the much-needed rest and relaxation which is necessary to rejuvenate the body and mind. This is one of the hardest kinds of stress to avoid because people think it is unavoidable and unmanageable $\{12\}$.

\section{Stress Management}

Stress can be managed effectively if taken into consideration and acted early on and it has to be managed on both personal as well as organizational level. $\{13\}$

\section{Personal Stress Management}

1. Restrict taking alcohol, tobacco, nicotine and caffeine to cope up with the stress.

2. Proper diet and regular workout (exercise, yoga) is necessary to make the body healthy and mind calm.

3. A hyper aggressive job such as policing job often need to take a higher workload than their capacity. The fear of not fulfilling the people's requirements can take a toll on person's body and mind. Expressing your capacities to your seniors and turning down potentially stress causing tasks is important individually to maintain the body and mind balance.

4. Try to avoid any unwanted conflict at workplace as well as home. Rather than trying to win any arguments just seek a solution which fits both the parties and move on with your day.

5. Training helps intercept stress through following measures:

a. Becoming acquainted with the stress signs. So we can deal with it early on without causing much harm to individual.

b. Using this to managing behaviour patterns in the early stress developmental phase. Stress progresses gradually. The early we tackle the stress; the less harm is done.

c. Reading the situation early on and developing an early plan to minimize the stressors.

d. Learning specialized skills for coping and relaxation and creating a lifestyle that helps us to deal with the stress.

e. Practicing the above in low stress conditions first to maximize the chances of better results and boosting of personal self-confidence which leads to selfmotivation.

\section{Organizational Stress Management}

1. A better and adequate assignment of financial resources within the police department will help in alleviating the majority of work stressors.

2. Department superiors should fabricate a plan describing their involvement and efforts in tackling the occupational stress. This helps in providing a positive mind set in employees that their employers are working towards tackling the stress and this will have a good effect on their work efficiency.

3. Police training academies should raise their standards and should give the real-world training. So when the police officers start their job they are well acquainted with the stress factors and can act upon it as early as possible.

4. Plan a "person-job-fit-analysis" for each new police officer. So that the new police officers get a job according to their capability. Because not all officers have the same mentality and same capacity to work in high demand conditions. Finding the perfect job for certain person will reduce the workplace stressors at their minimum. ${ }^{\{14\}}$

5. Facilitate worker participation in decisions regarding their tasks and how their job is accomplished.

6. Motivate open communication between the employees and their employers. So that a person can feel free to share their problems and it can be tackled early on. $\{15\}$

\section{CONCLUSIONS}

There is a high incidence of various addictions among the police personnel and the major reason is occupational stress.

\section{REFERENCES}

[1] Peñalba V, McGuire $H$, Leite JR. Psychosocial interventions for prevention of psychological disorders in law enforcement officers. Cochrane Database of Systematic Reviews 2008;(3):CD005601.

[2] Waters JA, Ussery W. Police stress: history, contributing factors, symptoms and interventions. Policing: An International Journal of Police Strategies \& Management 2007;30(2):169-88.

[3] Keinan G, Malach-Pines A. Stress and burnout among prison personnel: Sources, outcomes, and intervention strategies. Criminal Justice and Behavior 2007;34(3):380-98.

[4] Backman L, Arnetz BB, Levin D, et al. Psychophysiological effects of mental imaging training for police trainees. Stress Medicine 1997;13(1):43-8.

[5] Spector PE. Advanced topics in organizational behavior. Job satisfaction: application, assessment, causes and consequences. Thousand Oaks, CA, US: Sage Publications 1997: p. 26. 
[6] Lakshminarayanan R, Officer SA. An overview of strategic planning to combat occupational stress-need of the hour in the present Indian context. Senior Administrative Officer, National Institute of Virology, Indian Council of Medical Research 2008.

[7] Ragesh G, Tharayil HM, Raj MTP, et al. Occupational stress among police personnel in India. Open J Psychiatry \& Allied Sci 2017;8(2):148-52.

[8] Mitchell JT, Everly GS. Critical incident stress debriefing: an operations manual for CISD, defusing and other group crisis intervention services. Chevron Publishing 2001.

[9] Cross CL, Ashley L. Police trauma and addiction: coping with the dangers of the job. FBI Law Enforcement Bull. 2004;73(10):24-32.

[10] Nelson JE. Guide to drug abuse research terminology. Rockville, Maryland: 1982.
[11] Mustafa M, Illzam EM, Muniandy RK, et al. Causes and prevention of occupational stress. IOSR-JDMS 2015;14(11):98-104.

[12] Gearhardt AN, Grilo CM, DiLeone RJ, et al. Can food be addictive? Public health and policy implications. Addiction 2011;106(7):1208-12.

[13] Collins PA, Gibbs AC. Stress in police officers: a study of the origins, prevalence and severity of stress-related symptoms within a county police force. Occupational Medicine 2003;53(4):256-64.

[14] Channabasavanna SM, Gururaj G, Chaturvedi SK, et al. Occupational stress and mental health of police personnel in India. Bangalore: NIMHANS Publication 1996.

[15] Beheshtifar M, Zare E. Employee creativity: a compulsory factor in organizations. Interdisciplinary Journal of Contemporary Research in Business 2013;5(2):242-7. 